\title{
Influence of UV Polymerization Curing Conditions on Performance of Acrylic Pressure Sensitive Adhesives
}

\author{
Eun Seon $\mathrm{Kim}^{1,2}$ \\ Jae Heung Lee ${ }^{1}$ \\ Dong Hack Suh ${ }^{2}$ \\ Woo Jin Choi ${ }^{*, 1}$
}

\author{
${ }^{1}$ Chemical Materials Solutions Center, Korea Research Institute of Chemical Technology (KRICT), \\ Daejeon 34114, Korea \\ ${ }^{2}$ Department of Chemical Engineering, Hanyang University, Seoul 04763, Korea
}

Received August 26, 2020 / Revised December 17, 2020 / Accepted January 7, 2021

\begin{abstract}
Acrylic pressure sensitive adhesives (PSAs) were prepared by UV polymerization under varying curing conditions of both fast and slow curing, employing high- and low-intensity UV radiation, respectively. The influences of curing conditions and isobornyl acrylate (IBOA) content on PSA performance were comprehensively investigated by measurement of their rheological, thermal, and adhesive properties. In particular, rheological characterization was accomplished by several analytical methods, such as in situ UV rheology, frequency sweep, stress relaxation, and temperature ramp tests, to understand the effect of the UV curing process and

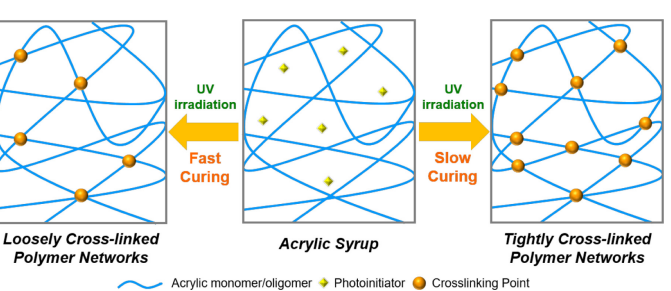
IBOA content on the viscoelastic behavior of acrylic PSAs. The slow-cured samples were observed to form more tightly crosslinked networks compared to the fast-cured. On the other hand, at high loading levels of IBOA, in the case of slow curing, the sample exhibited a contrasting trend, having the shortest stress relaxation time and the highest energy dissipation; this was due to molecular chain scission occurring in the crosslinked polymer during UV polymerization. Consequently, we successfully demonstrated the influence of monomer composition of acrylic PSAs, and that of curing conditions employed in UV polymerization. This study provides valuable insights for the development of crosslinked polymer networks of acrylic PSAs for flexible display applications.
\end{abstract}

Keywords: pressure sensitive adhesives (PSAs), UV polymerization, viscoelasticity, rheological properties, flexible displays.

\section{Introduction}

Pressure sensitive adhesives (PSAs) are polymer networks composed of crosslinked structures capable of bonding two surfaces together with a slight initial external pressure and a short contact time, owing to their viscoelastic properties..$^{1-5}$ Thus, they have been widely utilized in practical applications requiring specific properties, such as adhesion and cohesion; these are influenced by molecular parameters, including the monomer ratio, molecular weight, monomer chain structure but also crosslinking network characteristics. $^{6-12}$

Among a plethora of PSAs, acrylic PSAs are particularly attractive due to their numerous advantages, such as excellent optical performance, high temperature resistance, and favorable aging characteristics. Several studies have documented the molecular design of acrylic PSAs. ${ }^{13,14}$ Monomer structures comprising the combination of monomers are a critical factor to consider for achieving the desired acrylic PSA performance. The combination monomer of acrylic PSAs is composed of three major monomer types: ${ }^{15,16} 1$ ) soft monomers, such as 2-ehtyl hexyl acrylate, n-butyl

Acknowledgments: This work was supported by the Industrial Core Technology Development Program (10053627, Development of adhesive materials for foldable display with curvature lower than $2 \mathrm{~mm}$ and durability more than 100 thousand times) funded by the Ministry of Trade, Industry and Energy (MOTIE), Republic of Korea, and the Core Research Project at Korea Research Institute of Chemical Technology (KRICT) (KK1953-20) funded by the Ministry of Science and ICT (MSIT), Republic of Korea.

*Corresponding Author: Woo Jin Choi (wjchoi@krict.re.kr) acrylate, and isooctyl acrylate, exhibit low glass transition temperatures and play an important role in the control of adhesion properties; 2) hard monomers, such as isobornyl acrylate, ethyl acrylate, methyl acrylate, and vinyl acetate, display higher glass transition temperatures and can improve cohesion properties; 3) Functional monomers, such as acrylic acid, 2-hydroxy ethyl acrylate, and 2-hydroxy ethyl methacrylate, provide crosslinking sites for enhancing adhesion.

Previous studies have been limited to the consideration of only the monomer components of acrylic PSAs for obtaining desired properties. Several researchers have recently found that the physical properties of acrylic PSAs were directly affected by molecular factors, such as molecular weight, polydispersity, branching, and crosslinking network characteristics, which have been evaluated by rheological analyses of acrylic PSAs, resulting in improved physical properties. In particular, an existing strategy for improving specific performance entails the control of molecular structures. For example, Wang et al. observed that acrylic PSA assembly was influenced by the branching structure of various polyester side-chain lengths, which in turn affected the performance of these materials. ${ }^{7}$ Hwang et al. synthesized acrylic PSAs containing a cyclohexyl moiety to investigate the effect of chemical structures of acrylic substituents on adhesive performance. ${ }^{16}$

Among the approaches for modifying molecular structure, in order to develop crosslinked polymers, acrylic PSAs are prepared by various curing processes, such as via solution, emulsion, and UV polymerization. Solvent-based polymerization is a lengthy and energy-intensive process and the products contain numerous 
volatile organic compounds (VOCs), resulting in increased production costs and environmental pollution. ${ }^{14,17}$ While UV polymerization enacts rapid combination monomer conversion to crosslinked networks within a few minutes and is environmentally benign (the use of toxic catalysts and solvents is avoided). ${ }^{18-22}$ Although the UV polymerization approach is not suitable for the fabrication of thick products due to the limitations of UV light, this process has been successfully applied for the production of various industrial materials, such as medical products, coatings, paints, and adhesives. ${ }^{19}$ Previous studies have investigated the effect of various photoinitiators on the properties of PSAs generated by UV polymerization systems. ${ }^{23}$ The curing conditions are another important factor in the development of crosslinked networks because PSA properties are dramatically affected by UV intensity and exposure time. ${ }^{24}$ Hence, UV polymerization curing conditions should be investigated to understand the effects of physical properties on the formation of crosslinked networks of acrylic PSAs, and thereby optimize their performance.

The objectives of this study entail the preparation of acrylic PSAs employing varying isobornyl acrylate (IBOA) contents and curing conditions for UV polymerization, i.e., a fast curing condition with high UV intensity, and a slow curing condition with low UV intensity. Emphasis was placed on elucidating the effects of curing condition and UV intensities of the curing process on polymer network features and adhesive performances of acrylic PSAs by rheological analysis. Thus, this study provides a simple approach for achieving the desired acrylic PSA performance for flexible display applications.

\section{Experimental}

\subsection{Materials}

2-Ethyl hexyl acrylate (2-EHA), 2-hydroxyethyl acrylate (2-HEA), butyl acrylate (BA), isobornyl acrylate (IBOA), and 1,6-hexanediol diacrylate (HDDA) were purchased from Sigma-Aldrich. Irgacure 184 was purchased from Ciba and used as a photoinitiator. Toluene was purchased from Samchun Pure Chemical and used as received without further purification.

\subsection{Synthesis and preparation of acrylic PSAs}

The chemical structures and formulations of the synthesized acrylic PSAs are presented in Figure 1. Acrylic monomers (2-EHA, BA, 2-HEA, and IBOA) were stirred with HDDA at 0.15 parts per hundred resin (phr), and Irgacure 184 of 0.1 phr at room temperature for $10 \mathrm{~min}$. The formulation was designated as PSAnumber (the increasing order of IBOA content $(1,2,3$, or 4 )) in Figure 1(b). The mixture was coated at a thickness of $500 \mu \mathrm{m}$ onto corona-treated polyethylene terephthalate (PET) films using an auto bar coater (GBC-A4, GIST, Republic of Korea). For UV polymerization and crosslinking reactions the samples were placed in a UV irradiation apparatus and irradiated with a 24 $\mathrm{mW} / \mathrm{cm}^{2} \mathrm{UV}$ lamp as a $365 \mathrm{~nm}$ light source for $60 \mathrm{~s}$, and a $6 \mathrm{~mW} /$ $\mathrm{cm}^{2} \mathrm{UV}$ lamp as a $365 \mathrm{~nm}$ light source for $4 \mathrm{~min}$. UV light intensity was measured with a Silver Line UV Radiometer (UV-DESIGN, Germany). UV polymerization was performed at room temperature by UV irradiation in a light protection box. The thickness of the acrylic PSA samples was approximately $500 \mu \mathrm{m}$. The PSA sample designations included curing conditions, namely fast (i.e., $24 \mathrm{~mW} / \mathrm{cm}^{2}$ for $60 \mathrm{~s}$ ) or slow (i.e., $6 \mathrm{~mW} / \mathrm{cm}^{2}$ for $4 \mathrm{~min}$ ), and formulation information. For example, PSA which was generated at a high UV intensity $\left(24 \mathrm{~mW} / \mathrm{cm}^{2}\right.$ for $\left.60 \mathrm{~s}\right)$ with the formulation of PSA-1 was designated as F-PSA-1.

\subsection{Characterization of acrylic PSAs}

To examine the chemical structure of the acrylic PSAs, attenuated total reflectance-Fourier transform infrared (ATR-FTIR) spectra were measured at room temperature on a spectrometer

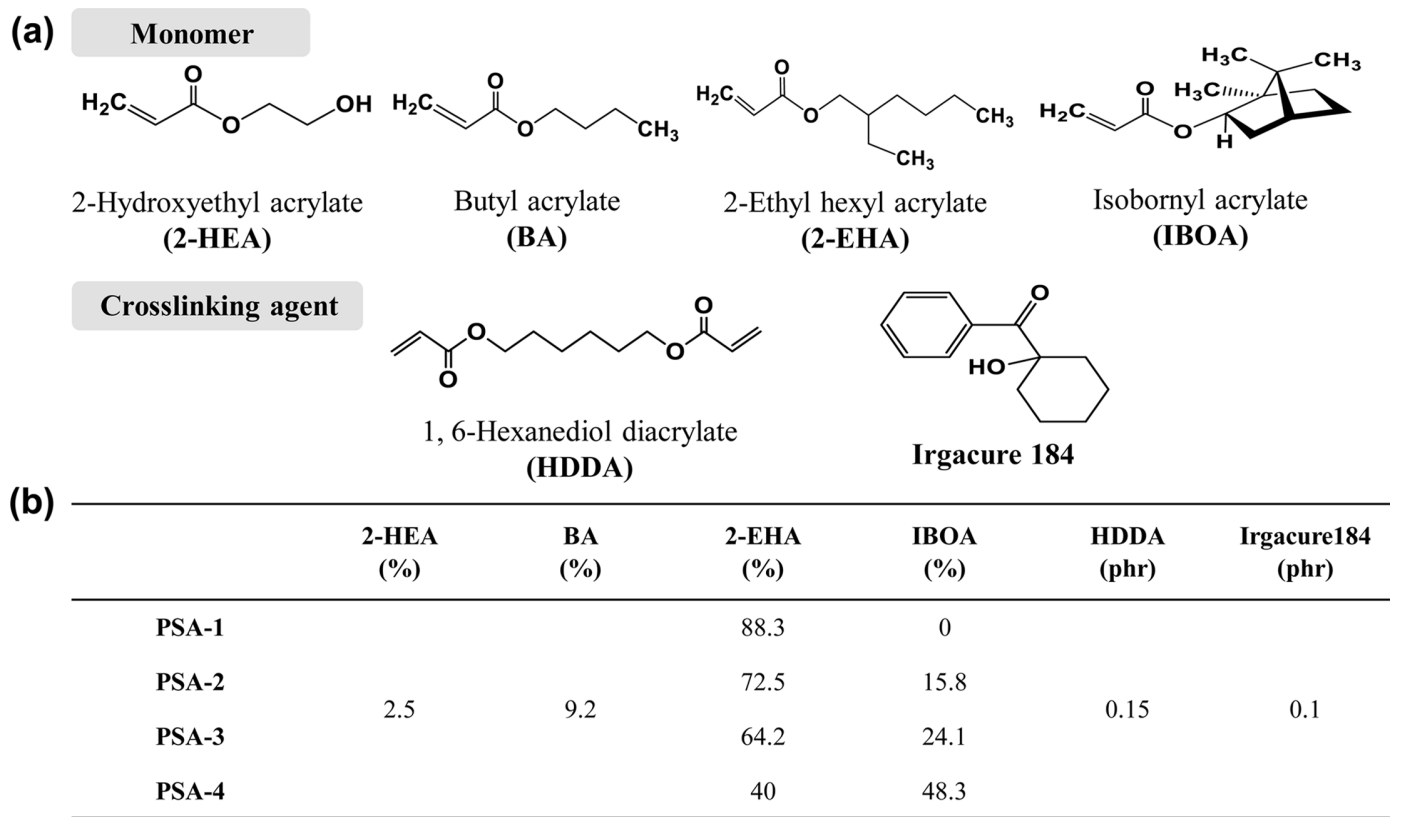

Figure 1. Preparation of acrylic PSAs: (a) chemical structures of the monomers and crosslinking agent and (b) formulation for the acrylic PSAs samples. 
(Nicolet 5700, Thermo Fisher Scientific Inc., USA), with a wavenumber range of $4000-650 \mathrm{~cm}^{-1}$ and a resolution of $4 \mathrm{~cm}^{-1}$.

In situ crosslinking rheological experiments were conducted on a rotational rheometer (ARES-G2, TA Instruments, USA) with a $25 \mathrm{~mm}$ aluminum bottom plate and a $20 \mathrm{~mm}$ quartz upper plate, allowing UV light to travel vertically upward into the sample. In situ UV measurements were performed using a UV light guide accessory connected to a $200 \mathrm{~W}$ mercury arc bulb UV source (Lumens Dynamic, Omnicure S2000, filter 320-500 nm, Excelitas Technologies Corp., USA). The UV light intensity was calibrated prior to each measurement using a Silver Line UV Radiometer. The gap size in these experiments was $500 \mu \mathrm{m}$. The reaction process of time sweep by in situ UV radiation was followed as a function of time at a fixed strain of $1 \%$ in the linear viscoelastic region (LVR) at a constant frequency of 6.28 $\mathrm{rad} / \mathrm{s}$ and UV intensity of 6 or $24 \mathrm{~mW} / \mathrm{cm}^{2}$. To evaluate the viscoelastic properties of the acrylic PSAs, all rheological tests were conducted on the same rheometer with a parallel-plate geometry of $8 \mathrm{~mm}$ in diameter and a gap of $500 \mu \mathrm{m}$, under nitrogen atmosphere. The rheological tests were strain sweep, frequency sweep, stress relaxation, temperature ramp, and step strain sweep. The amplitude strain sweep was performed at a constant frequency of $6.28 \mathrm{rad} / \mathrm{s}$ and deformation ranging from $0.1 \%$ to $200 \%$ for determining the LVR. The frequency sweep was performed over a frequency range of 0.1 to $100 \mathrm{rad} / \mathrm{s}$, keeping the strain constant at $3 \%$ at a constant frequency of $6.28 \mathrm{rad} / \mathrm{s}$ at $25^{\circ} \mathrm{C}$. The stress relaxation analysis of the acrylic PSA samples was conducted at $25^{\circ} \mathrm{C}$ at a fixed strain of $30 \%$ in the LVR for up to $300 \mathrm{~s}$ at a constant frequency of $6.28 \mathrm{rad} / \mathrm{s}$. The stress and stress relaxation modulus $\left(G_{\mathrm{r}}\right)$ were measured as a function of time. The temperature ramp test was conducted from -50 to $100^{\circ} \mathrm{C}$, keeping the strain constant at $3 \%$, at a constant frequency of $6.28 \mathrm{rad} / \mathrm{s}$. The step strain sweep test was carried out to investigate the recovery ability and the elastic response of the samples to applied shear strain, which ranged from low (strain $=2 \%$, frequency $=6.28 \mathrm{rad} / \mathrm{s}$, and time $=100 \mathrm{~s}$ ) to high (strain $=200 \%$, frequency $=6.28 \mathrm{rad} / \mathrm{s}$, and time $=100 \mathrm{~s}$ ), and the process was repeated for 4.5 cycles.

The glass transition temperatures $\left(T_{\mathrm{g}}\right)$ of the acrylic PSAs were investigated using a differential scanning calorimetry (DSC, Q1000, TA Instruments, USA). The specimens were heated from 30 to $300^{\circ} \mathrm{C}$ at a scanning rate of $10^{\circ} \mathrm{C} / \mathrm{min}$ under a constant nitrogen flow of $50 \mathrm{~mL} / \mathrm{min}$.

To evaluate the gel content, sections of the acrylic PSAs (approximately $200 \mathrm{mg}$ ) were placed in toluene $(2 \mathrm{~mL})$ at room temperature for $72 \mathrm{~h}$. Toluene and soluble components were then removed by filtration, and the residual gel was dried in a vacuum oven for $6 \mathrm{~h}$ at $25^{\circ} \mathrm{C}$ and weighed. The gel content was calculated using Eq. (1): ${ }^{25}$

Gel content $(\%) \frac{W_{r}}{W_{i}} \times 100$

where $W_{\mathrm{i}}$ and $W_{\mathrm{r}}$ indicate the initial and residual weight of the PSA sample, respectively.

Optical transmittances of the acrylic PSAs were measured in the wavelength range of 300 to $2400 \mathrm{~nm}$ using a UV/Vis/NIR spectrophotometer (U-4100, Hitachi, Japan). The thickness of all acrylic PSAs deposited on transparent colorless polyimide (CPI, KOLON Industry, Republic of Korea) substrates was 500 $\mu \mathrm{m}$; CPI film was chosen as it has recently been used in flexible display devices.

The adhesive performances of acrylic PSAs were tested against stainless steel test plates. The substrates were cleaned before testing by dispensing toluene onto their surface and wiping them with Kimwipes. The substrate cleaning process was repeated at least three times. The cleaned substrates were placed in a vacuum desiccator for $1 \mathrm{~h}$ before testing. To evaluate the adhesion performance of the acrylic PSAs, their peeling resistance was measured by the conventional $180^{\circ}$ peel adhesion test, as defined by adhesion and release testers (AR-1000, Chem Instruments Inc., USA). The PSA samples of PSAs-coated CPI films (approximately $500 \mu \mathrm{m}$ in thickness) were cut into strips $(25 \mathrm{~mm} \times 175 \mathrm{~mm})$ and after removing the release layer, adhered onto the test substrates using light finger pressure. To achieve uniform contact between the adhesive layer and the substrates, the PSA-coated CPI films were applied to the substrate using a $2 \mathrm{~kg}$ hand roller in each direction. The test samples were stored under ambient conditions for $24 \mathrm{~h}$ before testing. In each peel strength test, the sample strip was peeled from the surface at a peeling rate of $300 \mathrm{~mm} / \mathrm{min}$. The tests for each sample were repeated five times, and the results were averaged.

\section{Results and discussion}

\subsection{UV polymerization of acrylic PSAs}

In UV polymerization systems, the curing conditions affect the properties of the samples that determine the characteristics of crosslinked network structures. In this approach, we synthesized acrylic PSAs via various curing processes, namely 1) at a fast curing condition with high UV intensity (designated as FPSA-number), and 2) at a slow curing condition with low UV intensity (designated as S-PSA-number), to fabricate adhesives with distinct performances for flexible display applications.

Figure 2 illustrates the FT-IR spectra of acrylic PSAs generated by UV polymerization with varying curing condition and IBOA content. All of the samples displayed the absorption peaks originated from acrylic monomers at 2961, 2876, and $1736 \mathrm{~cm}^{-1}$ for $-\mathrm{CH}_{2}-,-\mathrm{CH}_{3}$, and $\mathrm{C}=\mathrm{O}$ stretching, respectively. ${ }^{26}$ The spectra of all the samples were similar regardless of the curing condition and IBOA content. To confirm that the UV polymerization proceeded perfectly, the $\mathrm{C}=\mathrm{C}$ stretching absorption bands $(1636$, 1407 , and $810 \mathrm{~cm}^{-1}$ ) were analyzed, as an indication of the degree of polymerization. ${ }^{27-29}$ The $\mathrm{C}=\mathrm{C}$ absorption peak at 1636 $\mathrm{cm}^{-1}$ of F-PSA-1, F-PSA-4, and S-PSA-1 was weak, while it was absent in the spectrum of S-PSA-4, indicating that all acrylic monomers containing $\mathrm{C}=\mathrm{C}$ bonds had reacted to develop a crosslinking structure. Thus, the curing condition and the increase in IBOA content have an appreciable influence on crosslinking structure formation during UV polymerization.

\subsection{Rheological properties of acrylic PSAs}

To understand the effects of the UV curing process on visco- 

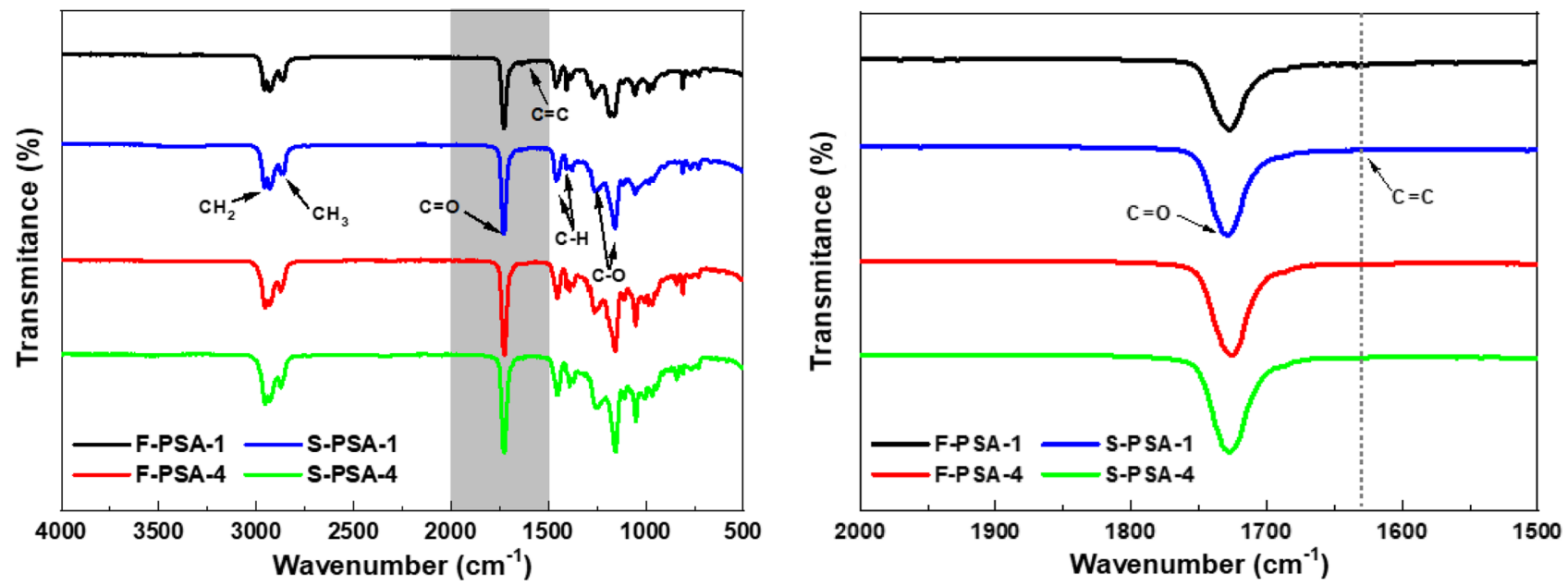

Figure 2. FT-IR spectroscopy of acrylic PSAs by UV polymerization with varying curing condition and IBOA content; (Left) Full curve of all system and (Right) magnified curve from $1500 \mathrm{~cm}^{-1}$ to $2000 \mathrm{~cm}^{-1}$.
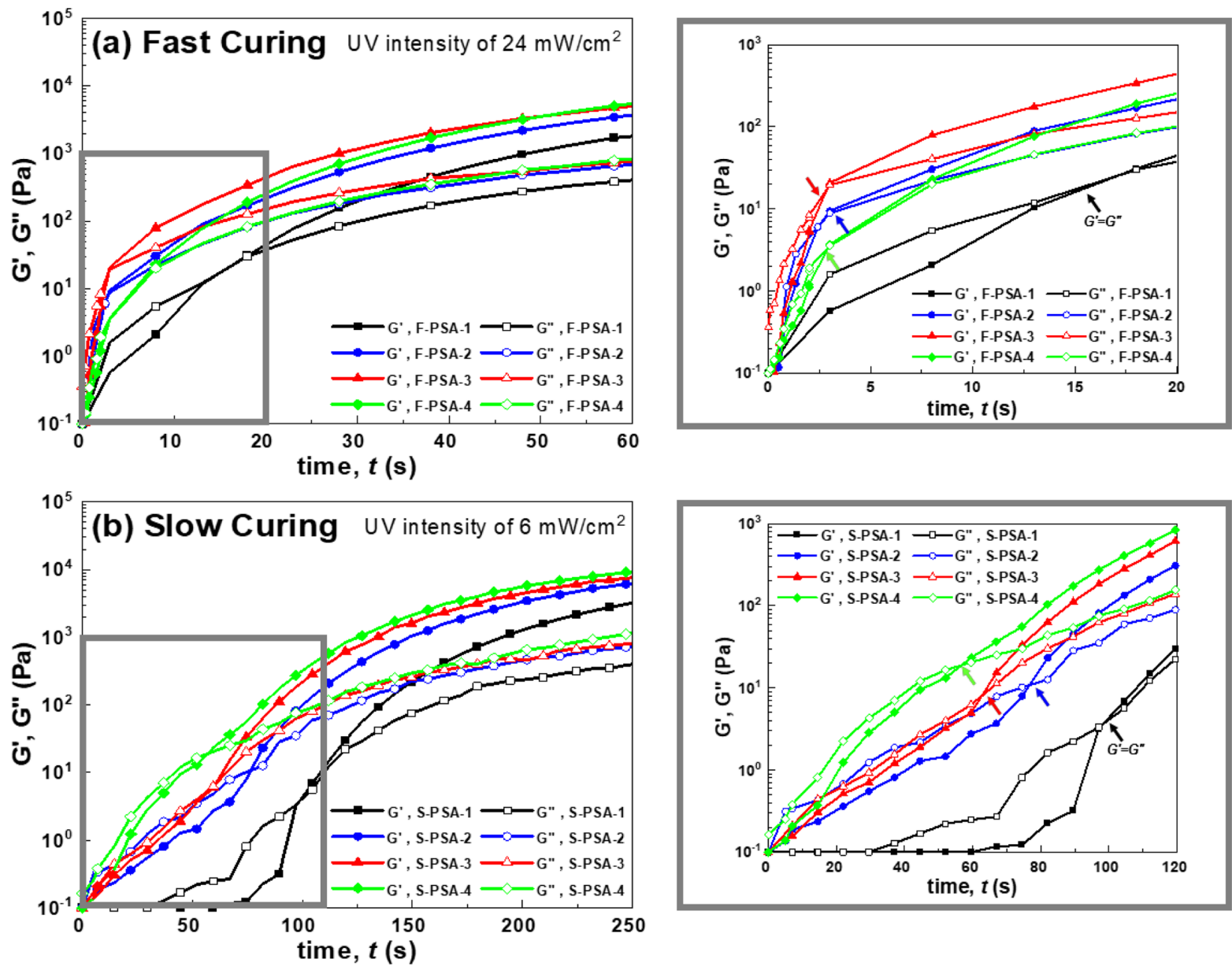

Figure 3. Time sweep of acrylic PSAs as measured by the in-situ UV rheology at a different curing condition of (a) fast curing (at UV intensity of 24 $\mathrm{mW} / \mathrm{cm}^{2}$ ) and (b) slow curing (at UV intensity of $6 \mathrm{~mW} / \mathrm{cm}^{2}$ ); (Left) Full curve of all system and (Right) magnified curve.

elastic behavior, a variety of rheological experiments were performed. The in situ crosslinking behaviors of the acrylic PSAs were characterized using dynamic oscillatory rheology under UV irradiation. Figure 3 shows the time sweep of the acrylic PSAs at a UV intensity of $24 \mathrm{~mW} / \mathrm{cm}^{2}$ (designated as fast curing), and $6 \mathrm{~mW} / \mathrm{cm}^{2}$ (designated as slow curing). Table 1 displays the crosslinking characteristics of the acrylic PSAs, generated at various IBOA content and UV intensities, as measured by dynamic rheology.

The curing conditions directly affect curing kinetics and final physical properties of the acrylic PSAs in the UV polymerization system. In the case of both fast and slow curing of acrylic 
Table 1. Summary of crosslinking behaviors of acrylic PSAs as measured by in-situ UV rheology under varying curing conditions

\begin{tabular}{ccccc}
\hline & Sample & UV intensity $\left(\mathrm{mW} / \mathrm{cm}^{2}\right)$ & $G^{\prime}-G^{\prime \prime}$ crossover time $(\mathrm{s})$ & $G^{\prime}$ at $1,440 \mathrm{~mJ} / \mathrm{cm}^{2}(\mathrm{~Pa})$ \\
\hline \multirow{3}{*}{ Fast } & F-PSA-1 & \multirow{2}{*}{24} & 3 & 2,052 \\
curing & F-PSA-2 & & 2.3 & 4,371 \\
& F-PSA-3 & & 2.0 & 5,580 \\
& F-PSA-4 & \multirow{2}{*}{6} & 104.5 & 7,486 \\
\hline \multirow{2}{*}{ Slow } & S-PSA-1 & & 82.0 & 3,084 \\
curing & S-PSA-2 & & 67.0 & 6,099 \\
& S-PSA-3 & & 59.3 & 7,418 \\
\hline
\end{tabular}

PSAs, the $G^{\prime}$ value of the acrylic monomer mixture increased by several orders of magnitude after UV irradiation, indicating that the mixture formed crosslinked polymers via UV polymerization. In addition, the $G^{\prime}$ value increased with increasing IBOA content in this system, indicating that IBOA content affected the formation of the crosslinking network.

During UV irradiation, the crosslinking reaction starts, and this reaction results in a dramatic increase in $G^{\prime}$ than $G^{\prime \prime}$. As shown in Figure 3, the $G^{\prime}$ values of the fast- and slow-cured samples were monitored over time during UV irradiation, and their curves exhibited different tendencies because the reaction rates of acrylic monomers differ in UV polymerization. ${ }^{30-33}$ To analyze these results quantitatively, we examined $G^{\prime}-G^{\prime \prime}$ crossover time, as that signified the point at which liquid-like behavior changed to solidlike behavior. The $G^{\prime}-G^{\prime \prime}$ crossover time of the slow-cured samples was longer than that of the fast-cured samples, implying that high UV intensity facilitated the formation of crosslinking structures. For example, $G^{\prime}$ of F-PSA-4 was equal to $250 \mathrm{~Pa}$ at $20 \mathrm{~s}$, while $G^{\prime}$ of S-PSA-4 had only reached $1.2 \mathrm{~Pa}$ at $20 \mathrm{~s}$. In addition, the $G^{\prime}-G^{\prime \prime}$ crossover time of all the samples decreased with increasing IBOA content, indicating that IBOA played an important role in the rapid formation of crosslinking structures. As mentioned previously, the final modulus of the acrylic PSAs can be affected by the curing condition of UV polymerization. Although slow curing samples showed lower $G^{\prime}$ values at $20 \mathrm{~s}$ compared to fast curing samples, the final $G^{\prime}$ values showed higher values in the samples prepared by slow curing condition. For example, the final $G^{\prime}$ value of F-PSA- 4 was approximately $7.5 \mathrm{kPa}$, while that of S-PSA-4 was approximately $9.1 \mathrm{kPa}$. The final $G^{\prime}$ values of all the samples also increased with increasing IBOA content. It was found that the final $G^{\prime}$ values of all the samples were dependent on the curing condition and their IBOA content, as these factors played a greater role in the development of crosslinking networks at longer curing time, and that slow curing resulted in improved conversion efficiency during UV polymerization.

Figure 4 shows the frequency sweep results of the acrylic PSAs with fast and slow curing conditions obtained on an oscillatory rheometer within linear viscoelastic regions. For all the samples, $G^{\prime}$ exhibited a higher value than $G^{\prime \prime}$ over the range of frequencies (i.e. $G^{\prime}>G^{\prime \prime}$ ), as shown in Figure 4(a) and (b). This implies that all the acrylic PSAs formed a crosslinking structure via UV polymerization due to the addition of HDDA as a crosslinker regardless of UV curing conditions. The $G^{\prime}$ value of the slow-cured samples was markedly higher than that of the fast-cured samples at equal formulations because the $G^{\prime}$ value
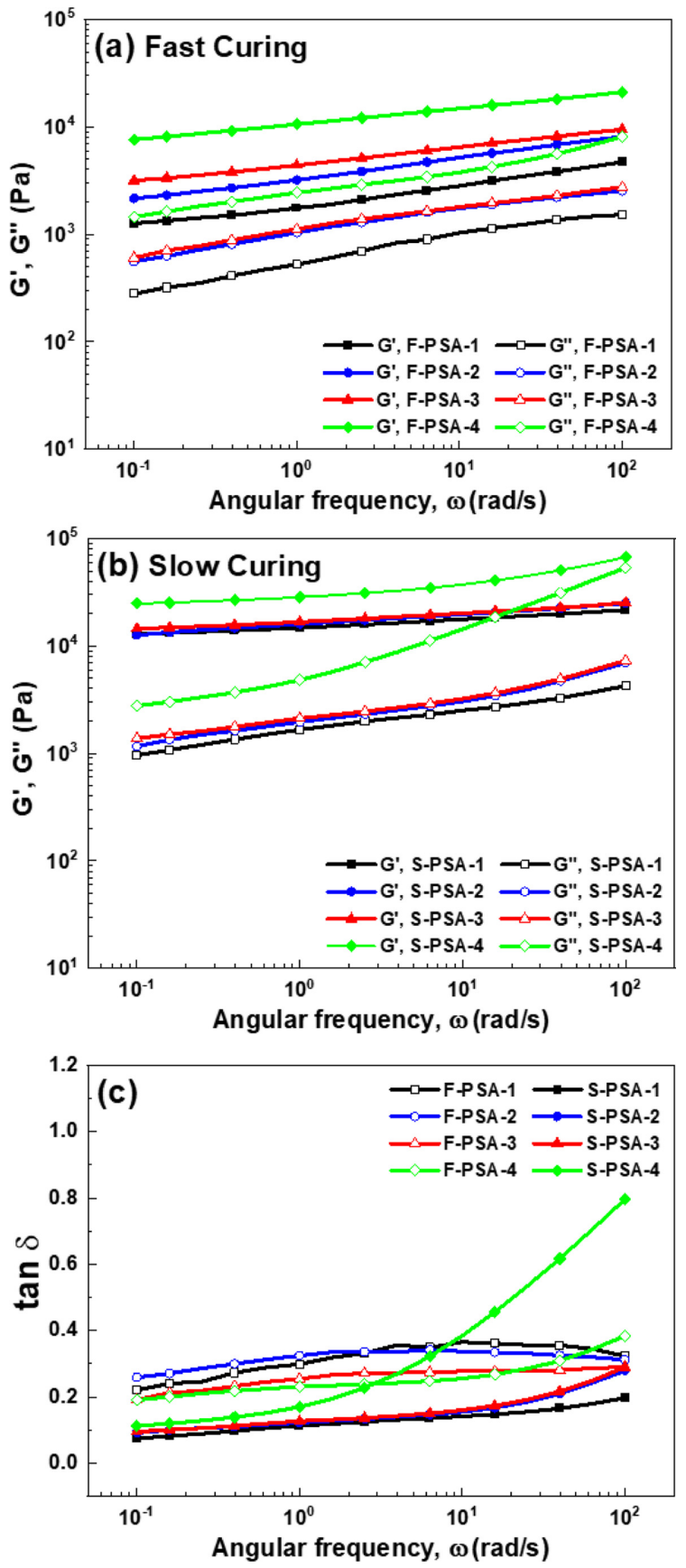

Figure 4. Frequency sweep results of acrylic PSAs as function of angular frequency at $25^{\circ} \mathrm{C}$ of test temperature: storage $\left(G^{\prime}\right)$ and loss modulus $\left(G^{\prime \prime}\right)$ of acrylic PSAs with (a) fast curing and (b) slow curing, and (c) $\tan \delta$, respectively. 
depends on the extent of crosslinking in the UV polymerization system. This result implies that a lower UV intensity coupled with a longer curing time is beneficial for the improvement of crosslinking density by a more complete crosslinking reaction. The $G^{\prime}$ values of all the samples increased with increasing IBOA content, so the introduction of IBOA influenced the properties of acrylic PSA, enabling the restriction of chain mobility due to bulky structure. In addition, for the fast curing samples, the $G^{\prime}$ values differed markedly with the variation of IBOA content over the measured range of frequencies. However, for the slowcuring samples, $G^{\prime}$ was independent of frequency and its magnitude (approximately $1.7 \times 10^{4} \mathrm{~Pa}$ ) varied minimally, except in the case of S-PSA. Figure 4(c) illustrates the plot of dissipative character evolution (defined as $\tan \delta=G^{\prime \prime} / G^{\prime}$ ) of the acrylic PSAs, against a range of frequencies. The $\tan \delta$ value of the fast-cured samples was higher than that of slow-cured samples, implying that the former displayed more viscous behavior than the slowcured samples. For all of the samples, $\tan \delta$ was independent of frequency, except in the cases of F-PSA-4 and S-PSA-4. In particular, The S-PSA-4 had a different tendency which exhibited the increase of $\tan \delta$ over the whole frequency range despite the highest $G^{\prime}$ in all the samples. These results indicate that the acrylic PSA system to the development of crosslinked networks is more susceptible to the increase of IBOA with bulky structure as well as curing conditions with longer curing time in UV polymerization simultaneously.

To gain a deeper understanding of the mechanics and relaxation of crosslinked networks undergoing small deformations, a stress relaxation experiment was performed on the acrylic PSAs. We further explored whether the relaxation time was reflected in the chain mobility characteristics of the crosslinking network, which was evaluated as the time required to relax to 1/e of the normalized stress relaxation modulus. ${ }^{34-36}$ Figure 5 shows the normalized stress relaxation of the acrylic PSAs as a function of time at $25^{\circ} \mathrm{C}$. To evaluate chain mobility in the crosslinking networks, the normalized stress relaxation modulus of the acrylic PSAs was determined. As shown in Figure 5(a) and (b), the curves for the fast and slow curing acrylic PSAs exhibited differing tendencies. For the fast curing samples, the relaxation times were $0.68,1.73$, 99.1, and 297 s for F-PSA-1, F-PSA-2,

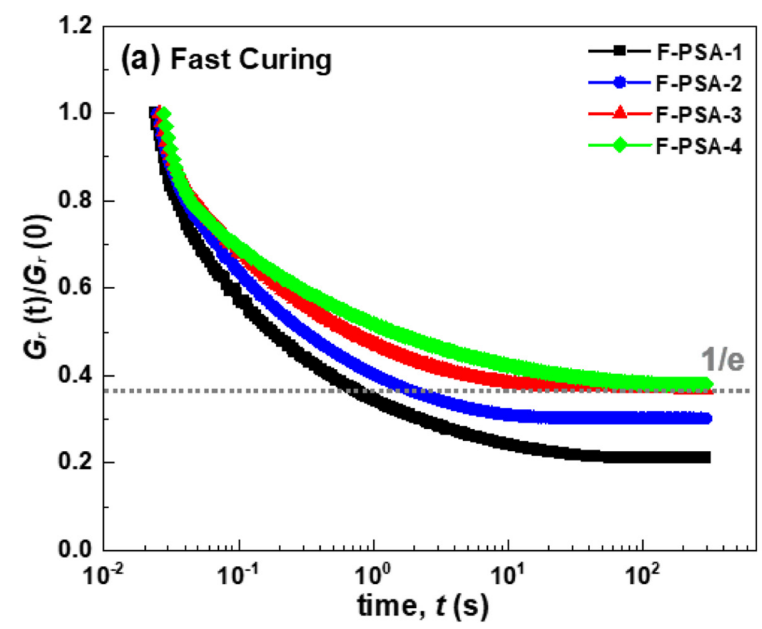

F-PSA-3, and F-PSA-4, respectively. The relaxation time increased with increasing IBOA content for fast curing in the UV polymerization system, indicating that the addition of IBOA can influence chain mobility in acrylic PSA networks. For example, F-PSA-4 exhibited the longest relaxation time and poor chain mobility compared to that of F-PSA-1. For the slow-cured samples, the relaxation time was not obtained as an exact value by this calculation method. However, we demonstrated that the relaxation time increased in the following order: S-PSA-1 > S-PSA-2 > SPSA-3 > S-PSA-4, indicating that the relaxation time increased with decreasing IBOA content, as shown in Figure 5(b). This was in contrast to the results obtained for the fast-cured samples. For example, S-PSA-4 achieved relaxation much faster, exhibiting a shorter relaxation time than S-PSA-1, despite having a higher IBOA content. This phenomenon suggests that the curing condition of a lower UV intensity coupled with a longer curing time enhances molecular chain scission and defects in crosslinking networks. In other words, this curing process simultaneously involves crosslinking and molecular chain scission. ${ }^{37-39}$

The recovery abilities of the acrylic PSAs generated with fast and slow curing can be characterized by strain sweep and continuous strain tests using an oscillatory rheometer. Figure 6(a) and (b) depict the strain amplitude sweeps of the PSA-1 and PSA-4 samples, respectively. For all the samples, the $G^{\prime}$ value was higher than that of $G^{\prime \prime}$ over the measured range of frequencies, indicating that these samples have formed a crosslinked network. In addition, both $G^{\prime}$ and $G^{\prime \prime}$ displayed constant plateau values within linear viscoelastic regions (LVR), markedly changing above the critical strain region. The critical strain of PSA-4 samples $(\gamma>73 \%)$ was higher than that of PSA-1 samples ( $\gamma>54 \%)$. Figure 6(c) and (d) display the continuous step strain results obtained for the F-PSA-1 and PSA-4 samples, respectively. For PSA-1 samples, $G^{\prime}$ decreased from $\sim 4.2$ to $\sim 3.0 \mathrm{kPa}$ for F-PSA-1, and from $\sim 17.8$ to $\sim 11.3 \mathrm{kPa}$ for S-PSA-1 under high strain, and $\tan \delta$ increased from $\sim 0.32$ to $\sim 0.38$ for F-PSA-1, and from $\sim 0.09$ to 0.25 for S-PSA-1 under high strain. For PSA- 4 samples, $G^{\prime}$ decreased from $\sim 21.1$ to $\sim 16.2 \mathrm{kPa}$ for F-PSA-4, and from $\sim 31.8$ to $\sim 28.8 \mathrm{kPa}$ for S-PSA-4 under high strain, respectively and $\tan \delta$ increased from $\sim 0.27$ to $\sim 0.32$ for F-PSA-4 and from $\sim 0.40$ to 0.48 for $\mathrm{S}$-PSA-4 under large strain. These results suggest that the forma-

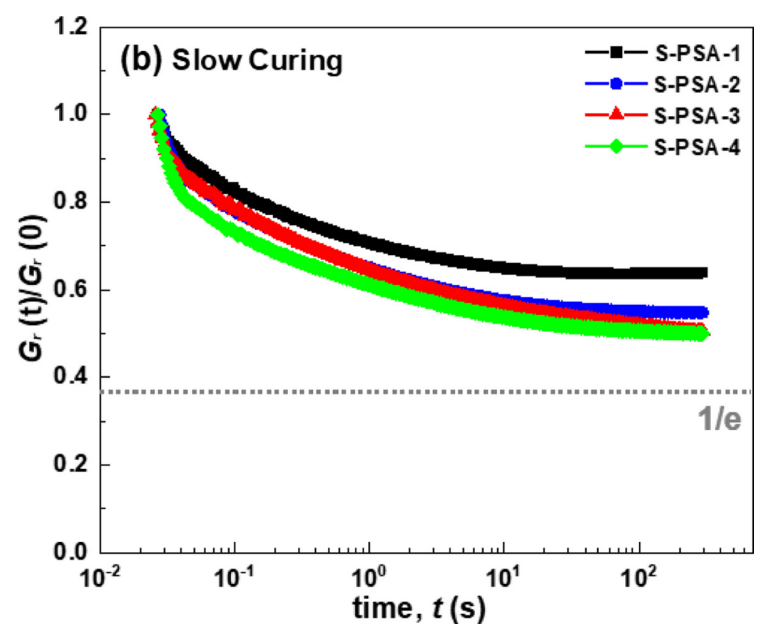

Figure 5. Normalized stress relaxation modulus of acrylic PSAs; (a) fast curing and (b) slow curing as a function of time at $25^{\circ} \mathrm{C}$ of test temperature. 

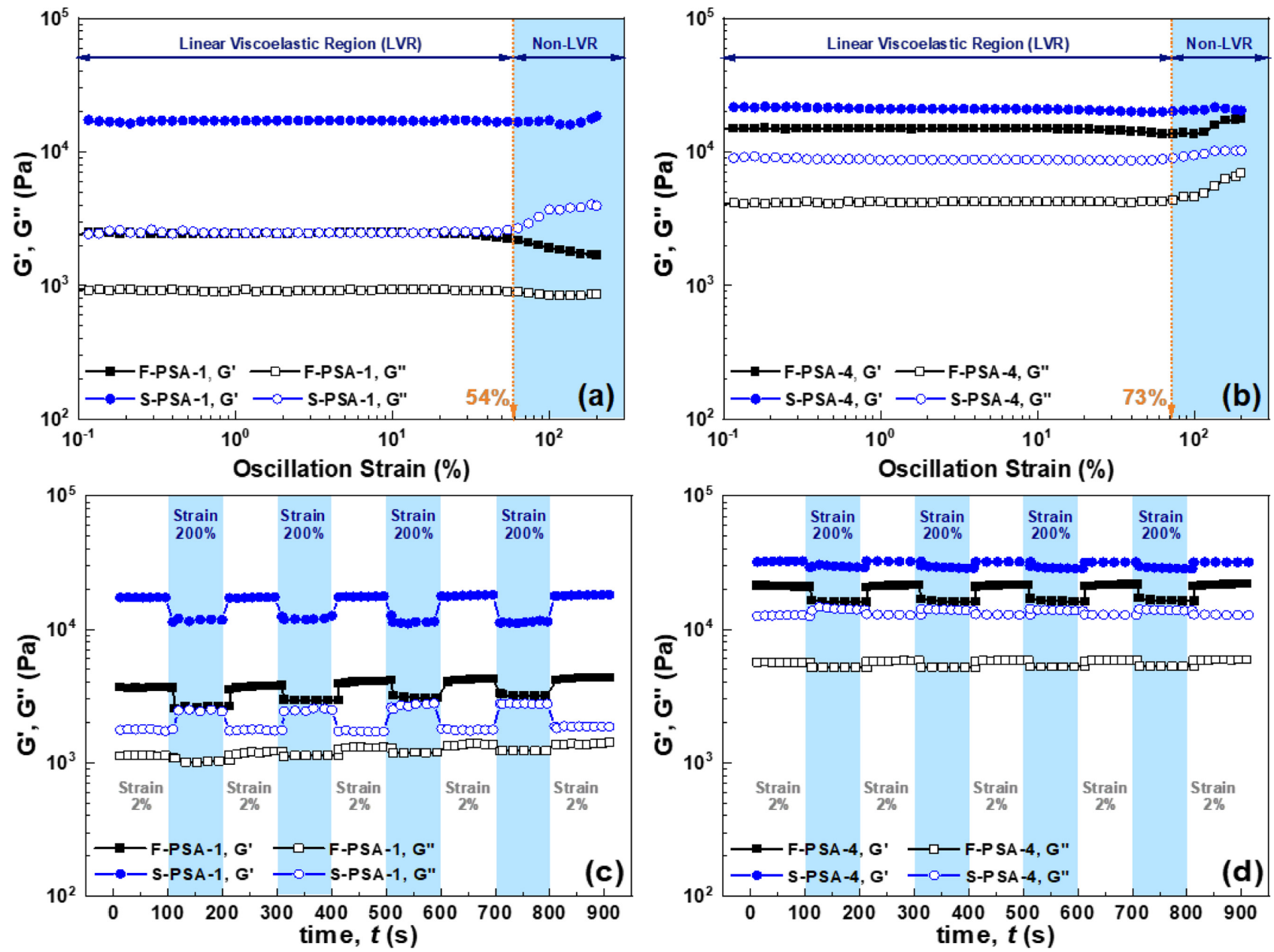

Figure 6. Recovery abilities of acrylic PSAs with different curing conditions characterized by the rheology test; $G^{\prime}$ and $G^{\prime \prime}$ values on strain sweep of (a) PSA-1 and (b) PSA-4 and continuous step strain measurement of (c) PSA-1 and (d) PSA-4 with applied oscillatory strain alternated between $2 \%$ and $200 \%$ at fixed angular frequency.

tion of a crosslinking network structure is influenced not only by the slow curing condition but also by IBOA content. Furthermore, given the applied alternative strain of all the samples, the $G^{\prime}$ value of these samples could re-increase rapidly to the initial value. In other words, the crosslinking networks of these sam- ples required less than $100 \mathrm{~s}$ to recover their original state. It was found that all the samples exhibited excellent recovery capabilities, which is advantageous for flexible display applications.
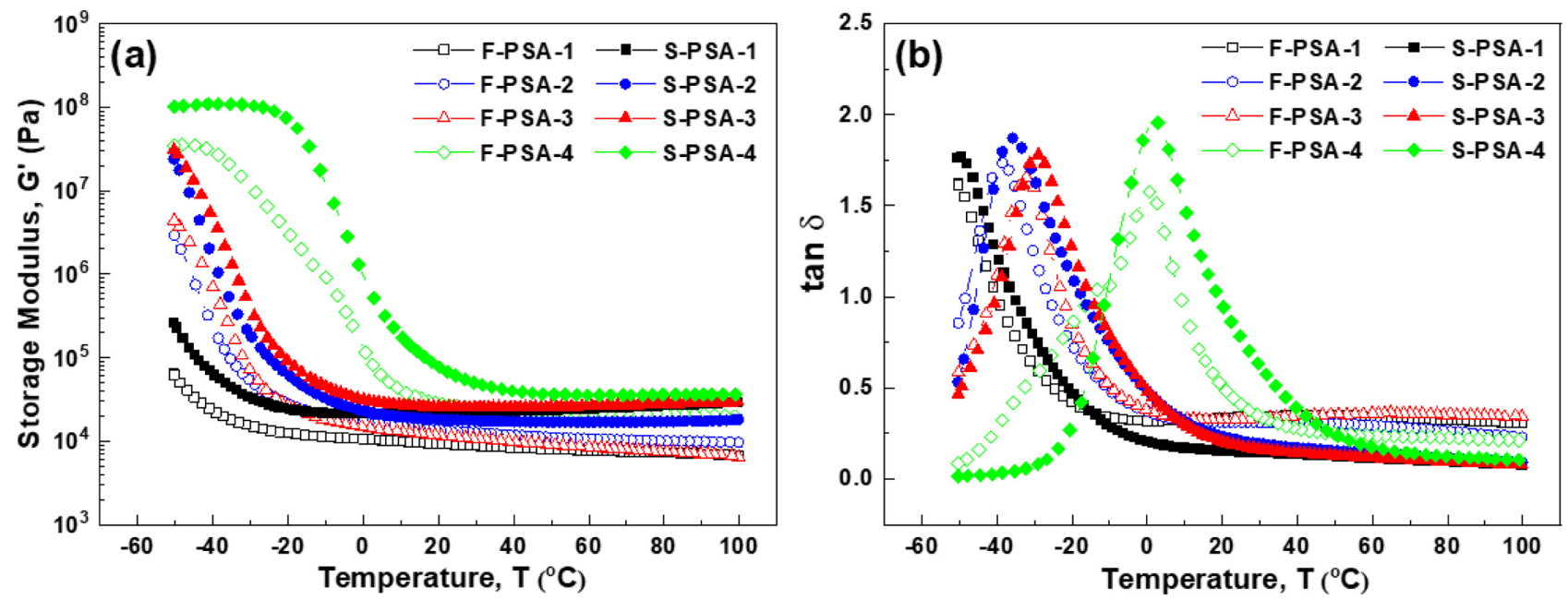

Figure 7. Temperature dependence of acrylic PSAs with different curing conditions characterized by rheology test; (a) $G^{\prime}$ and (b) tan $\delta$ on temperature sweep test of acrylic PSAs with different curing conditions. 
Table 2. Storage modulus $\left(G^{\prime}\right)$ and glass transition temperature $\left(T_{\mathrm{g}}\right)$ of acrylic PSAs generated under different curing conditions

\begin{tabular}{|c|c|c|c|c|c|c|}
\hline & \multirow{2}{*}{ Sample } & \multicolumn{3}{|c|}{ Storage modulus $G^{\prime}(\mathrm{Pa})$} & \multicolumn{2}{|c|}{ Glass transition temperature $T_{\mathrm{g}}(\mathrm{C})$} \\
\hline & & at $-20{ }^{\circ} \mathrm{C}$ & at $25^{\circ} \mathrm{C}$ & at $60^{\circ} \mathrm{C}$ & DSC & ARES \\
\hline \multirow{4}{*}{ Fast curing } & F-PSA-1 & $1.37 \times 10^{4}$ & $9.02 \times 10^{3}$ & $7.68 \times 10^{3}$ & -61.5 & - \\
\hline & F-PSA-2 & $3.02 \times 10^{4}$ & $1.30 \times 10^{4}$ & $1.06 \times 10^{4}$ & -43.7 & -38.6 \\
\hline & F-PSA-3 & $4.10 \times 10^{4}$ & $1.12 \times 10^{4}$ & $8.42 \times 10^{3}$ & -40.3 & -32.2 \\
\hline & F-PSA-4 & $6.48 \times 10^{6}$ & $2.64 \times 10^{4}$ & $2.19 \times 10^{4}$ & -3.18 & 0.56 \\
\hline \multirow{4}{*}{ Slow curing } & S-PSA-1 & $2.73 \times 10^{4}$ & $2.16 \times 10^{4}$ & $2.42 \times 10^{4}$ & -60.6 & - \\
\hline & S-PSA-2 & $1.02 \times 10^{5}$ & $1.78 \times 10^{4}$ & $1.69 \times 10^{4}$ & -41.9 & -35.8 \\
\hline & S-PSA-3 & $1.73 \times 10^{4}$ & $2.56 \times 10^{4}$ & $2.63 \times 10^{4}$ & -38.1 & -28.9 \\
\hline & S-PSA-4 & $9.53 \times 10^{7}$ & $5.77 \times 10^{4}$ & $3.55 \times 10^{4}$ & -2.60 & 1.29 \\
\hline
\end{tabular}

\subsection{Thermal properties of acrylic PSAs}

The influence of curing conditions and IBOA content on the thermal behavior of the acrylic PSAs in the UV polymerization system were investigated by rheology and DSC measurements. The results are displayed in Figure 7, and the thermal properties are summarized in Table 2.

Figure 7 illustrates $G^{\prime}$ and $\tan \delta$ values of the acrylic PSA samples as a function of temperature, as characterized by a rheometer. In general, $G^{\prime} v$ s. temperature curves display a glassy state, glass transition, and a rubbery plateau. As shown in Figure 7(a), the curves of glassy state for all the samples could not be observed because their glass transition temperatures $\left(T_{\mathrm{g}}\right)$ were below the measured ranges, except in the case of S-PSA-4. Regarding the rubbery plateau, the $G^{\prime}$ values of the slow-cured samples were higher than those of fast-cured. As the content of IBOA in the acrylic PSAs increased, the $G^{\prime}$ values increased and the rubbery plateau shifted to a higher temperature region. For example, SPSA-1 had a broader temperature range for the rubbery plateau of all the samples and was also more likely to have a higher $G^{\prime}$ value, hence it displayed the highest thermal stability among the tested PSAs within a wide temperature range of $-35.8^{\circ} \mathrm{C}$ to $100^{\circ} \mathrm{C}$. On the contrary, S-PSA-4 in the rubbery plateau shifted considerably to a higher temperature at approximately $19.3^{\circ} \mathrm{C}$ and exhibited a high $G^{\prime}$ value in the low temperature region, implying that this sample was unsuitable as a PSA. These results indicate that the increase in $G^{\prime}$ value over $10^{5} \mathrm{~Pa}$ in the low temperature region is not suitable for flexible display applications because of the decrease of adhesive properties. Figure 7(b) presents the $\tan \delta$ values of the acrylic PSAs generated with various curing conditions and IBOA content. $T_{\mathrm{g}}$ values are reflected at the starting point of moving polymer chains in the crosslinking network and are defined as the peak temperatures of $\tan \delta^{40}$ The $T_{\mathrm{g}}$ values of the slow-cured samples were slightly higher than those of the fast-cured, and $\tan \delta$ of the slow-cured samples was lower in the high-temperature region, indicating that the slow curing process was beneficial for the formation of more stable crosslinking networks. In addition, as the IBOA content in the acrylic PSAs increased, the $\tan \delta$ maximum was shifted appreciably to the higher temperature region, indicating an increase in $T_{\mathrm{g}}$. Therefore, increasing IBOA content led to restricted chain mobility in the crosslinking networks of acrylic PSAs. Based on this analysis, it can be concluded that the thermal behavior of acrylic PSAs is affected by IBOA content more than by curing conditions.

\subsection{Crosslinking networks of acrylic PSAs}

Several studies suggest that $T_{\mathrm{g}}$ is closely related to crosslinking density in the crosslinking networks because the increase in crosslinking density can restrict chain mobility. ${ }^{41,42}$ It was found that the acrylic PSAs developed a three-dimensional continuous network between the polymer chains following UV polymerization. The number of crosslinking sites in the acrylic PSAs increased with the increase in IBOA content, resulting in higher density networks. ${ }^{14}$ This phenomenon can be explained by Fig-
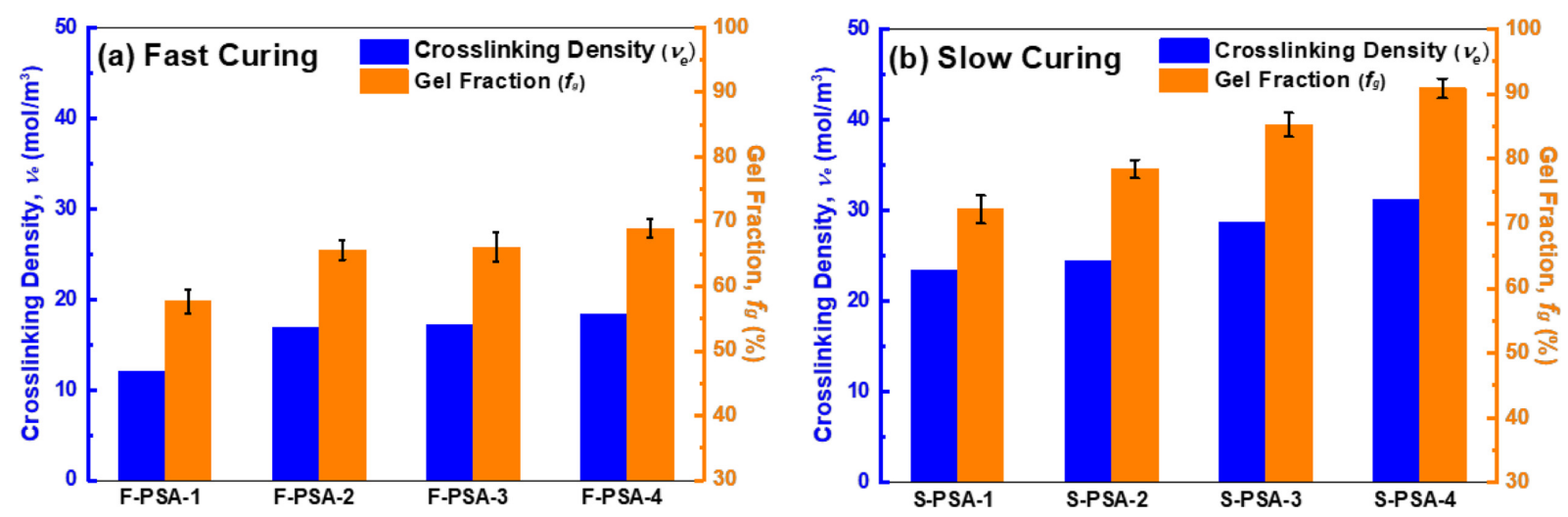

Figure 8. Crosslinking density $\left(v_{\mathrm{e}}\right)$ and gel fraction $\left(f_{\mathrm{g}}\right)$ of acrylic PSAs with different curing conditions; (a) fast curing and (b) slow curing. 
ure 8, which illustrates the crosslinking densities $\left(v_{\mathrm{e}}\right)$ and gel fractions $\left(f_{\mathrm{g}}\right)$ of the acrylic PSAs obtained by fast and slow curing.

In general, the degree of crosslinking is approximated by gel fraction measurements used to calculate the insoluble portion of crosslinking networks. ${ }^{41-43}$ The $f_{\mathrm{g}}$ value gradually increased with increasing IBOA content. In addition, the $f_{\mathrm{g}}$ values of the slow-cured samples were higher than those of the fast-cured. These results suggest that both the curing conditions and the IBOA content can strongly influence the formation of crosslinking networks in acrylic PSAs. In general, the $f_{\mathrm{g}}$ value is directly correlated with the rubbery plateau modulus and crosslink density. ${ }^{29,45}$ We additionally calculated $v_{\mathrm{e}}$ by using the following Eq. (2): $:^{44-46}$

$v_{e}=\frac{G}{R T}$

where $G$ is determined from $G^{\prime}$ at the onset of the rubbery plateau, $R$ is the universal gas constant $\left(8.314 \mathrm{~J}^{-1} \mathrm{~K}^{-1}\right)$, and $T$ is the absolute temperature at which $G$ is located. Evidently, the $v_{\mathrm{e}}$ values of the slow-cured samples are higher than those of the fast-cured samples. Also, the $v_{\mathrm{e}}$ value increased with increasing IBOA content, which was attributed to the increasing degree of crosslinking between the polymer chains. These trends were analogous to those observed for the gel fraction results of all the samples. Furthermore, the findings detailed in Figures 7 and 8 confirmed that the increase in crosslinking density is a direct consequence of an increased $T_{\mathrm{g}}$ of the acrylic PSAs.

\subsection{Pressure-sensitive adhesive properties}

In general, acrylic PSAs need to exhibit high transmittance (> 95\%) to be applied to flexible displays. ${ }^{47,48}$ Figure 9 (a) shows the optical transmittances of acrylic PSAs produced by fast and slow curing in the wavelength range of $400-800 \mathrm{~nm}$. The optical transmittance of the fast-cured samples was higher than that of the slow-cured samples, and these values were independent of IBOA content, except in the case of S-PSA-4. In other words, the optical transmittance decreased in the slow-cured samples, implying that the slow curing process has been directly affected by crosslinking and molecular chain scission in the acrylic PSA networks. ${ }^{47}$

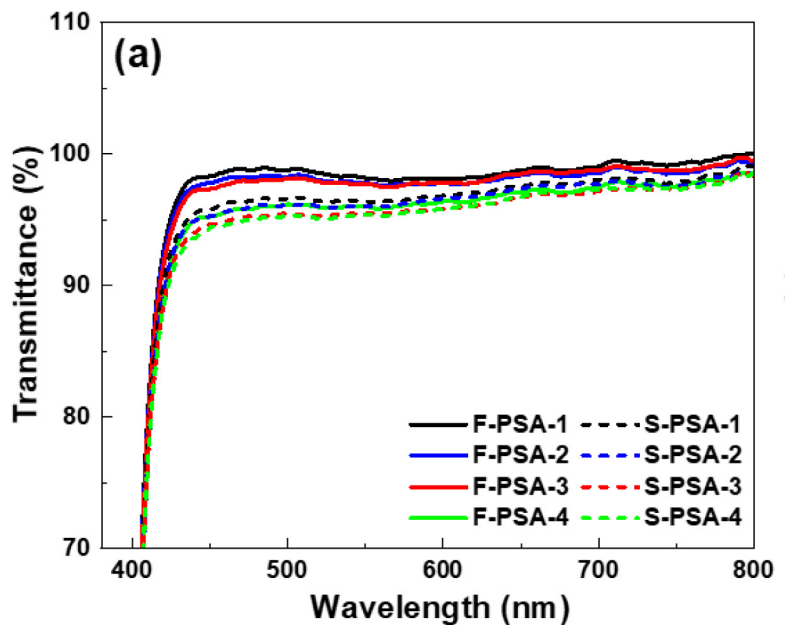

Nonetheless, the transmittance values of all the samples were $95 \%$ or more, indicating that these samples exhibit excellent transparency in the visible wavelength range and are suitable for application in flexible display devices. Figure 9(b) shows the yellow indices $\left(\mathrm{b}^{*}\right)$ calculated by ASTM E313 from spectrophotometric data of acrylic PSAs generated by fast and slow curing. The $b^{*}$ value provides an index of the sample color characteristics, indicating the degree of yellowness. ${ }^{50}$ The yellow indexes of the acrylic PSAs increased significantly with increasing IBOA content and were higher for the slow curing process than for the fast. The yellow color is caused by significant molecular damage to the crosslinked polymer during UV polymerization. ${ }^{51-53}$ Thus, controlling the chemical composition and curing conditions of UV polymerization is important for obtaining a highly transparent acrylic PSA with a low yellow index.

In general, the peel strength is closely related to the rheological properties of a material. In particular, the peel strength increases with increasing $\tan \delta$ and decreasing $G^{\prime}$ and crosslinking density. ${ }^{6,54,55}$ Figure 10 depicts the peel strength of acrylic PSAs generated by fast and slow curing. The peel strength of fast-cure samples decreased with increasing IBOA content, except in the case of F-PSA-4. For the slow-cured samples, the peel strength displayed a similar tendency to that of the fast-cured samples, so the value decreased with increasing IBOA content except in

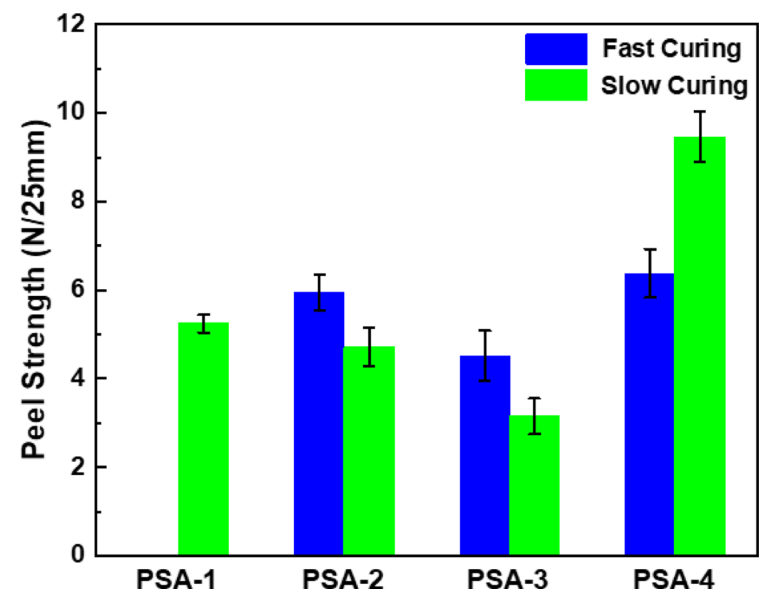

Figure 10. Peel strength of acrylic PSAs with different curing condition.

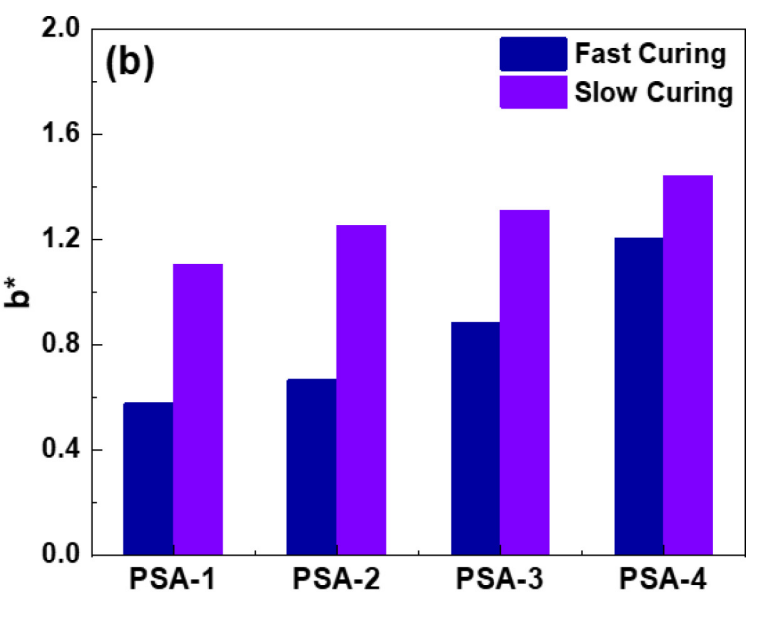

Figure 9. (a) Optical transmittance and (b) yellow index ( $b^{*}$ ) of acrylic PSAs with different curing condition. 

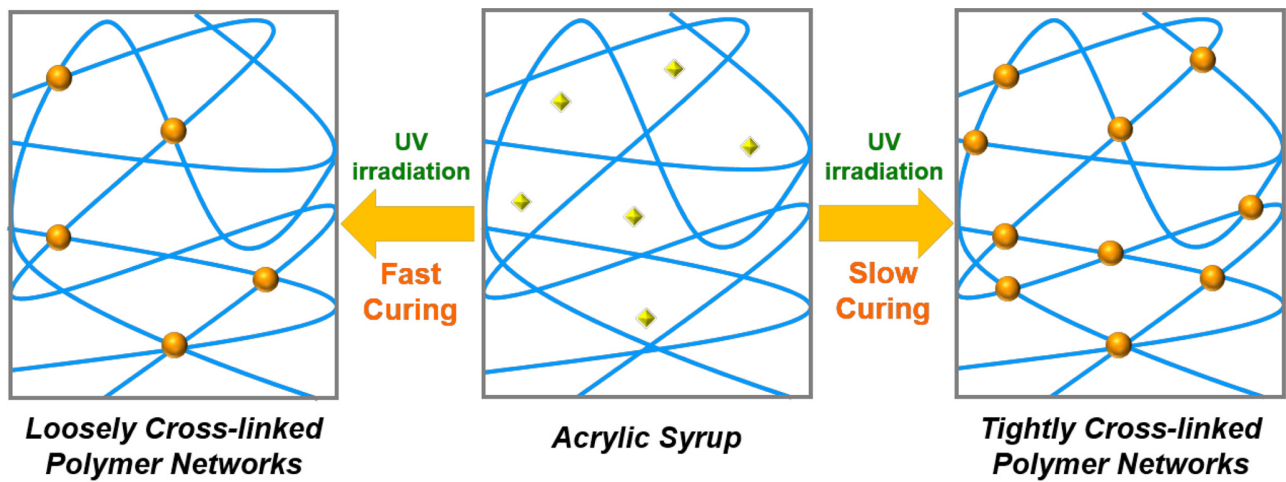

Acrylic monomer/oligomer $\rightarrow$ Photoinitiator $\mathrm{C}$ Crosslinking Point

Figure 11. Schematic diagram for the crosslinked network structure of acrylic PSAs in UV polymerization with fast and slow curing.

the case of S-PSA-4. Also, the peel strengths of the fast-cured samples were generally higher than those of the slow-cured. This is because the fast-cured samples display more liquid-like behavior than the slow-cured samples from rheology analysis. The $\tan \delta$ values of the slow-cured samples were higher than those of the fast-cured in high frequency region despite having a higher $G^{\prime}$ and crosslinking density, except in the case of S-PSA1and S-PSA-2. This is because the slow-cured samples can be affected by chain scission due to the longer curing time in the UV polymerization system. In particular, the peel strength of SPSA-4 was significantly higher than that of the other samples, despite having the highest $G^{\prime}$ and crosslinking density. This is because these samples simultaneously underwent crosslinking reactions as well as molecular chain scission during UV polymerization, resulting in high $\tan \delta$ values in the frequency sweep and relaxation time, leading to stress relaxation. Unfortunately, the peel strength of F-PSA- 1 could not be determined, as the sample was not amenable to measurement. It was found that the curing conditions and the IBOA content influenced the peel strength of the acrylic PSAs. These results suggest that the peel strength is directly associated with the $\tan \delta$ value, as mentioned in chapter 3.2.

Figure 11 shows the development of the crosslinked network structure of acrylic PSAs in UV polymerization with fast and slow curing. Throughout these analyses, these notable results are that the slow curing samples became tightly crosslinked polymer networks compared to the fast curing samples. Therefore, the curing conditions significantly influenced the formation of crosslinking networks for the acrylic PSAs in UV polymerization.

\section{Conclusions}

We evaluated the properties of acrylic PSA crosslinked networks produced by UV polymerization under varying curing conditions, including fast and slow curing with high or low intensity UV radiation, respectively, as well differing IBOA contents, for the development of PSAs suitable for flexible displays. Based on the rheological characterization and thermal and adhesive properties of the synthesized acrylic PSAs, we found that the slow curing of samples increased their modulus and thermal stability, which contribute significantly to increasing crosslinking density, compared to fast curing. In addition, IBOA is a bulky monomer for the rapid development of crosslinking networks during the UV polymerization process. However, S-PSA-4, despite having the highest $G^{\prime}$ value and crosslinking density, exhibited a shorter relaxation time than that of other slow-curing samples. These phenomena suggest that the UV polymerization process is affected by not only the crosslinking reaction but also by molecular chain scission occurring in crosslinked polymers to a higher degree in prolonged operations. In conclusion, the chemical compositions of PSAs as well as the curing conditions of UV polymerization, have significant effects on determining the material properties of acrylic PSAs intended for flexible display applications.

\section{References}

(1) M. C. Vu, G. Park, Y. Bae, M. J.Yu, T. K. An, S. Lee, and S. Kim, Macromol. Res., 24, 1070 (2016).

(2) Y. Kim, S. Park, H. Kim, and J. Hong, Macromol. Res., 16, 128 (2008).

(3) K. J. Arrington, S. C. Radzinski, K. J. Drummey, T. E. Long, and J. B. Matson, ACS Appl. Mater. Interfaces, 10, 26662 (2018).

(4) X. Zhang, Y. Ding, G. Zhang, L. Li, and Y. Yan, Int. J. Adhes. Adhes., 31, 760 (2011).

(5) S. Sun, M. Li, and A. Liu, Int. J. Adhes. Adhes., 41, 98 (2013).

(6) S. M. Taghizadeh, and D. Ghasemi, J. Appl. Polym. Sci., 120, 411 (2011).

(7) Y. Wang, F. Weng, J. Li, L. Lai, W. Yu, S. J. Severtson, and W. Wang, ACS Omega, 3, 6945 (2018).

(8) S. F. Dana, D. Nguyen, J. S. Kochhar, X. Liu and L. Kang, Soft Matter, 9, 6270 (2013).

(9) J. Back, D. Baek, K. Sim, G. Oh, S. Jang, H. Kim, and Y. Kim, Ind. Eng. Chem. Res., 58, 4331 (2019).

(10) M. Inutsuka, M. Haraguchi, M. Ozawa, N. L. Yamada, and K. Tanaka, ACS Macro Lett., 8, 267 (2019).

(11) J. Lee, T. Lee, K. Shim, J. Park, H. Kim, Y. Kim, S. Jung, Int. J. Adhes. Adhes., 74, 137 (2017).

(12) J. K. Kim, J. W. Kim, M. I. Kim, and M. S. Song, Macromol. Res., 14, 517 (2006).

(13) K. Y. Bae, D. H. Lim, J. W. Park, H. J. Kim, and H. M. Jeong, Polym. Eng. Sci., 53, 1968 (2013).

(14) M. Zhu, Z. Cao, H. Zhou, Y. Xie, G. Li, N. Wang, Y. Liu, L. Hed and X. Qu, RSC Adv., 10, 10277 (2020).

(15) Z. Czech and A. Butwin, J. Adhes. Sci. Technol., 23, 1689 (2009).

(16) S. Baek, S. Jang, and S. Hwang, Int. J. Adhes. Adhes., 64, 72 (2016).

(17) A. Lopez, E. Degrandi-Contraires, E. Canetta, C. Creton, J. L. Keddie, 
and J. M. Asua, Langmuir, 27, 3878 (2011).

(18) J. Kajtna, U. Šebenik, and M. Krajn, Int. J. Adhes. Adhes., 49, 18 (2014).

(19) S. Yamago and Y. Nakamura, Polymer, 54, 981 (2013).

(20) J. G. Lee, G. S. Shim, J. W. Park, H. J. Kim, and K. Y. Han, Int. J. Adhes. Adhes., 70, 249 (2016)

(21) C. Mendes-Felipe, J. Oliveira, I. Etxebarria, J. L. Vilas-Vilela, and S. Lanceros-Mendez, Adv. Mater. Technol., 4, 1800618 (2019).

(22) G. Park, H. Jung, K. Kim, J. Lim, J. Lee, S. Lee, J. H. Lee, and S. Kim, Macromol. Res., 23, 396 (2015).

(23) Z. Czech, A. Butwin, and J. Kabat, Eur. Polym. J, 47, 225 (2011).

(24) A. Patel, O. Kravchenko, and I. Manas-Zloczower, Polymers, 10, 125 (2018).

(25) A. Walker, M. Vratsanos, S. Kozawa, T. Askew, K. Hemmendinger, B. McGrail, N. Bedfordc, and G. Wnek, Soft Matter, 15, 7596 (2019).

(26) H. Zhou, Q. Li, T. Y. Lee, C. A. Guymon, E. S. Jonsson, and C. E. Hoyle, Macromolecules, 39, 8269 (2006).

(27) J. S. Oh, K. H. Choi, and D. H, Suh, ChemistrySelect, 3, 12836 (2018).

(28) H. Xu, F. Qiu, Y. Wang, W. Wu, D. Yang, and Q. Guo, Prog. Org. Coat., 73, 47 (2012).

(29) Y. Li and X. S. Sun, RSC Adv., 5, 44009 (2015).

(30) O. Konuray, X. Fernández-Francos, X. Ramis, and À. Serra, Polymers, 10, 178 (2018).

(31) F. Jiang and D. Drummer, Polymers, 12, 1080 (2020).

(32) R. Anastasio, W. Peerbooms, R. Cardinaels, and L. C. A. van Breemen, Macromolecules, 52, 9220 (2019).

(33) H. Gong, Y. Gao, S. Jiang, and F. Sun, ACS Appl. Mater. Interfaces, 10, 26694 (2018).

(34) Z. Liu, C. Yu, C. Zhang, Z. Shi, and J. Yin, ACS Macro Lett., 8, 233 (2019).

(35) F. Meng, R. H. Pritchard, and E. M. Terentjev, Macromolecules, 49, 2843 (2016).

(36) Y. J. Kwon, S. M. Hong, and C. M. Koo, J. Polym. Sci. Pol. Phys., 48, 1265 (2010).

(37) S. Lee, T. Lee, J. Park, C. Park, H. Kim, J. Song and J. Lee, J. Electron.
Mater., 43, 11, 4246 (2014).

(38) M. E. Nichols, J. L. Gerlock and C. A. Smith, Polym. Degrad. Stab., 56, 81 (1997).

(39) M. E. Nichols and J. L. Gerlock, Polym. Degrad. Stab., 69, 197 (2000).

(40) Y. Shangguan, J. Yang, and Q. Zheng, RSC Adv., 7, 15978 (2017).

(41) C. Liu, J. Huang, D. Yuan, and Y. Chen, Ind. Eng. Chem. Res., 57, 14527 (2018).

(42) Z. Cheng, M. Yan, L. Cao, J. Huang, X. Cao, D. Yuan, and Y. Chen, Ind. Eng. Chem. Res., 58, 3912 (2019).

(43) G. Shim, J. Kim, and H. Kim, J. Ind. Eng. Chem., 89, 139 (2020).

(44) H. Joo, Y. Park, H. Do, H. Kim, S. Song, and K. Choi, J. Adhes. Sci. Technol., 21, 575 (2007).

(45) R. Vendamme and W. Eevers, Macromolecules, 46, 3395 (2013).

(46) M. T. Brannum, A. D. Auguste, B. R. Donovan, N. P. Godman, V. M. Matavulj, A. M. Steele, L. T. J. Korley, G. E. Wnek, and T. J. White, Macromolecules, 52, 8248 (2019).

(47) S. Lee, J. Park, Y. Kwon, S. Kim, H. Kim, E. Kim, H. Woo, and J. Swidersk, Int. J. Adhes. Adhes., 38, 5 (2012).

(48) C. Park, S. Lee, T. Lee, and H. Kim, Int. J. Adhes. Adhes., 63, 137 (2015).

(49) S. Lee, J. Park, C. Park, Y. Kwon, H. Kim, E. Kim, H. Woo, S. Schwartz, M. Rafailovich, and J. Sokolov, Int. J. Adhes. Adhes., 44, 200 (2013).

(50) W. M. Laurence, The Effect of Sterilization on Plastics and Elastomers, Elsevier, Waltham, 2012, pp 61-62.

(51) R. Muller and G. Wilke, J. Coat. Technol. Res., 11, 6, 873 (2014).

(52) M. Shirai, Polym. J., 46, 859 (2014).

(53) Y. Sanai and K. Kubota, Polym. J., 52, 1153 (2020).

(54) J. Asaharaa, A. Takemuraa, N. Hori, H. Ono, and H. Matsui, Polymer, 45, 4917 (2004).

(55) J. Chopin, R. Villey, D. Yarusso, E. Barthel, C. Creton, and M. Ciccotti, Macromolecules, 51, 8605 (2018).

Publisher's Note Springer Nature remains neutral with regard to jurisdictional claims in published maps and institutional affiliations. 